$17^{\circ}$ ERGODESIGN

\& USIHC 2019

PUC-Rio, 11 a 13 de dezembro

Rio de Janeiro, RJ, Brasil $17^{\circ}$ Ergodesign - Congresso Internacional de Ergonomia e Usabilidade de Interfaces Humano Tecnológica: Produto, Informações Ambientes Construídos e Transporte

$17^{\circ}$ USIHC - Congresso Internacional de Ergonomia e Usabilidade

de Interfaces Humano Computador

\title{
Modelagem de Roupas Ergonomicamente Projetadas para Mulheres Portadoras de Nanismo Acondroplásico
}

\author{
Ergonomically Designed Clothing Modeling for Women with Achondroplasic \\ Dwarfism
}

\author{
BARBOSA, Gracineide H. \\ Serviço Nacional de Aprendizagem Industrial, Centro de Tecnologia da Indústria Química e

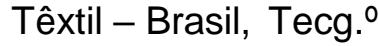 \\ Gracineide.hbgracinha@yahoo.com.br
}

RADICETTI, Elaine

Pontifícia Universidade Católica do Rio de Janeiro, Dep. de Artes \& Design - Brasil, M. Sc. eradicet@yahoo.com.br

CORREA, Maria José C.

Universidade CEUMA - Maranhão, Dep. de Design- Brasil, Esp.

\begin{abstract}
RESUMO
Este artigo consiste em desenvolver estudos ergonômicos e antropométricos para a criação de uma tabela de medidas corpo, através da medição de mulheres portadoras de nanismo acondroplásico, buscando o conforto, a qualidade, bem como, a estética através da ergonomia aplicada à roupa. Considerando a modelagem parte fundamental do design de produto na área do vestuário, as medidas estudadas estão de acordo com as normas e técnicas usuais para a construção de moldes ergonomicamente projetados, com foco nos membros superiores e inferiores e a curva acentuada no final da coluna vertebral. Os objetivos foram delimitados para entender melhor as principais necessidades das mulheres portadoras de nanismo, com relação ao uso da roupa. Foram discutidos no resultado deste estudo, benefícios e dificuldades relacionadas ao desenvolvimento de produtos de moda, ergonomicamente adequados para o público feminino em questão. Assim, de acordo com o diagnóstico efetuado entre a revisão de literaturas e as pesquisas de campo, constatou-se a relevância da ergonomia na modelagem para o desenvolvimento de produtos do vestuário que facilite o bem-estar e o conforto no uso das roupas para pessoas com acondroplasia, de acordo com as tendências da moda. Esta pesquisa demonstra a preocupação em desenvolver estudos da ergonomia na modelagem com medidas antropométricas adequadas para esse público e consumidor específico, permitindo assim, que sejam incluídos em uma sociedade plural, onde o futuro tecnológico dará suporte não só a criação de uma coleção, mas também a comercialização virtual.
\end{abstract}

Nanismo acondroplásico, ergonomia, modelagem, design de moda.

\begin{abstract}
This article consists of developing ergonomic and anthropometric studies to create a body measurement table by measuring women with achondroplasic dwarfism, seeking comfort, quality as well as, aesthetics through ergonomics applied to clothing. Considering that modeling is a fundamental part of product design in the field of clothing, the measures studied are in accordance with the usual norms and techniques for ergonomically designed pattern construction. Focusing on the upper and lower limbs and the steep curve
\end{abstract}




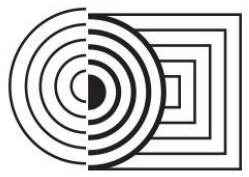

\section{$17^{\circ}$ ERGODESIGN \& USIHC 2019 \\ PUC-Rio, 11 a 13 de dezembro \\ Rio de Janeiro, RJ, Brasil}

$17^{\circ}$ Ergodesign - Congresso Internacional de Ergonomia e Usabilidade

de Interfaces Humano Tecnológica: Produto, Informações Ambientes

Construídos e Transporte

$17^{\circ}$ USIHC - Congresso Internacional de Ergonomia e Usabilidade

de Interfaces Humano Computador

at the end of the spine, the objectives to be contemplated were delimited to better understand the main needs of women with dwarfism regarding the use of clothing. The results of this study discussed the benefits and difficulties related to the development of ergonomically appropriate fashion products for the female audience concerned. Thus, according to the diagnosis made between the literature review and the field research, it was found the relevance of ergonomics in modeling for the development of clothing products that facilitate the well-being and comfort of wearing clothes for people with achondroplasia, according to fashion trends. This research demonstrates the concern to develop ergonomics studies in pattern makings with anthropometric measurements suitable for this specific audience and consumer, thus allowing them to be included in a plural society, where the technological future will support not only the creation of a collection, but also the virtual mechandise.

Achondroplasic dwarfism, ergonomics, pattern making, fashion design.

\section{INTRODUÇÃO}

A roupa é um produto indispensável ao indivíduo para que ele se comunique e seja incluído em um grupo ou em uma sociedade, tanto em momentos de laser ou no universo do trabalho. Vestir é um ato que deve proporcionar prazer e o uso de uma peça ou um conjunto, possa contemplar o conforto e a ergonomia para que seus usuários possam exercer o seu papel na sociedade com a liberdade, respeito, incluindo valores estéticos com o foco em suas conformações corporais, através de estudos ergonômicos de seus biotipos. Quando a conformação de um corpo muda, os seus movimentos e suas limitações também mudam e para as pessoas que nascem portadoras de alguma deficiência, muitas vezes os estudos em certas áreas ainda requerem progresso, para que sejam suficientes no papel da inclusão, onde os usuários se vistam e expressem seus sentimentos através da roupa, confiantes em fazerem parte de uma sociedade plural.

Neste contexto de valor social, o presente estudo objetivou avaliar e aproximar ao máximo o valor das medidas através de levantamento antropométrico do universo de mulheres portadoras de nanismo acondroplásico. Com base em uma amostragem de medições manuais e tabelas publicadas em pesquisas científicas, tendo como foco o dimensionamento do produto roupa com o uso das medidas ergonômicas, direcionadas para a indústria do vestuário, confirmando pela aplicação de uma perspectiva ampla sobre a qualidade, através da valorização pelo cliente, baseada no uso e na capacidade do produto para satisfazer suas necessidades, com diferenças em atributos ou ingredientes desejados pelos usuários, que ao adquirirem roupas disponíveis no mercado atual, as peças passam por adaptações de acordo com análises corporais feitas por costureiras que, empiricamente ajustam apenas medidas de comprimento e largura, sem adaptar as conformações do corpo, relacionadas aos seus movimentos básicos e extensos em suas funções.

O nanismo é estudado com maior frequência na área da medicina onde são analisados fatores genéticos, neurológicos e ortopédicos. Na área do vestuário, o corpo humano é estudado e analisado como suporte usuário do produto roupa, e para o desenvolvimento deste produto, faz-se necessário o levantamento antropométrico e o estudo ergonômico do biotipo, que neste trabalho foram pesquisadas mulheres portadoras de nanismo acondroplásico. A pesquisa investigou as dimensões corporais, para o desenvolvimento e criação de itens de vestuário propostos especificamente para este público, facilitando, de certa forma, o dia a dia destas pessoas, contemplando fatores estéticos, funcionais e ergonômicos, contribuindo para o estudo da modelagem do vestuário para o público em estudo.

Nanismo é um transtorno ou mutação genética que se caracteriza por uma deficiência no crescimento, que resulta numa pessoa com estatura baixa se comparada com a média da 


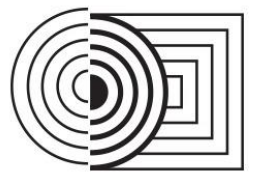

\section{$17^{\circ}$ ERGODESIGN \& USIHC 2019 \\ PUC-Rio, 11 a 13 de dezembro \\ Rio de Janeiro, RJ, Brasil}

$17^{\circ}$ Ergodesign - Congresso Internacional de Ergonomia e Usabilidade de Interfaces Humano Tecnológica: Produto, Informações Ambientes Construídos e Transporte

$17^{\circ}$ USIHC - Congresso Internacional de Ergonomia e Usabilidade de Interfaces Humano Computador

população de mesma idade e sexo.

Existem vários tipos de nanismo e cada um deles apresenta características específicas.

Segundo FURTADO L. (2015), o mais conhecido é a acondroplasia, uma desproporção característica do nanismo entre os tipos existentes, que pode ser hereditária ou fruto de uma mutação genética, em que os indivíduos formam um grupo em que sua estatura é bem menor do que a média esperada e costumam ser casos raros em suas famílias. Com base na análise do autor citado, sendo a acondroplasia o tipo mais comum, o trabalho focou no estudo deste biotipo para o desenvolvimento de uma coleção cápsula, com cinco peças de roupas ergonomicamente projetadas para essas mulheres.

De acordo com SOUZA S. de (2012), adultos com acondroplasia, apresentam estatura entre $1.20 \mathrm{~m}$ e $1.26 \mathrm{~m}$, que é semelhante à altura de uma criança de 6 a 7 anos de idade, de acordo com levantamento antropométrico do brasileiro infantil, RADICETTI E. (1999). Outras características são a curva acentuada no final da coluna vertebral, sendo notada por uma lordose lombar, cifose torácica, o Varo, que é o arqueamento das pernas (ligeiramente arqueadas), os pés que são curtos e largos e os limites na movimentação dos cotovelos, por não dobrar completamente devido à concentração de massa corporal nesta região.

De acordo com os autores citados e análise durante a pesquisa com mulheres portadora de nanismo acondroplásico, existem outras características observadas dentro desta classificação em estudo, como, os dedos das mãos, que por seu diâmetro maior que o padrão, as pontas dos dedos não se juntam, a circunferência do crânio é uma medida dentro dos parâmetros normais e apresentam os ossos são bem largos. Com o foco na modelagem, observou-se uma diferença grande entre as medidas da circunferência da cava que é pequena, em relação à circunferência do bíceps que é bem maior, considerada grande se comparada com a medida do bíceps de um indivíduo no tamanho padrão.

CERVAN E. A. (2008), afirma que embora considerada uma deficiência física, portadores de nanismo tendem a viver normalmente, no que se trata de longevidade $e$ produtividade. No entanto, existe uma maior propensão dos mesmos, ao desenvolvimento de distúrbios psicológicos, relacionados ao complexo de inferioridade e a insatisfação com a própria aparência.

Hoje, com o avanço da tecnologia em um mundo globalizado, esse grupo de pessoas portadoras de nanismo, começam a ter acessibilidade a ônibus, academia, mobiliários, aparelho de pressão infantil em consultórios para adultos, grupos de autoajuda, atividade física com orientação de neurocirurgião fisioterapeuta, melhor relacionamento no mercado de trabalho e acesso a redes sociais, compartilhando informações como manter uma qualidade de vida através da troca de informações desses avanços, para que as demais pessoas desse grupo possam ter acesso a esses benefícios.

Não existe produção em escala industrial para roupas de marcas atuantes no mercado atual, voltadas para o público portador de nanismo, apenas ateliers que trabalham sobencomenda, como exemplo, o trabalho da estilista Carina Casuscelli, da marca A Moda Está em Baixa, e costureiras que constroem a roupa direto sobre o corpo da cliente. Com isso, a dificuldade de encontrar peças que sirvam é enorme. Arrisca-se afirmar que tal escassez dificulte ainda mais o dia a dia desses indivíduos. Mesmo que o futuro seja a venda de roupas para este grupo de consumidores por e-commerce, porém, é preciso antes, conhecer o biotipo em questão e a forma de se modelar uma roupa para este corpo, o que muitas vezes apenas mudam as medidas de comprimento e largura de uma base construída para um padrão de corpo normal, sem considerar as diferenças anatômicas que o corpo com características do nanismo acondroplásico possuem. De acordo com essa demanda, buscou-se embasamento teórico para tentar oferecer produtos de qualidade a esse público tão especial e específico. 


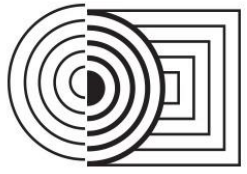

\section{$17^{\circ}$ ERGODESIGN \& USIHC 2019 \\ PUC-Rio, 11 a 13 de dezembro \\ Rio de Janeiro, RJ, Brasil}

$17^{\circ}$ Ergodesign - Congresso Internacional de Ergonomia e Usabilidade de Interfaces Humano Tecnológica: Produto, Informações Ambientes Construídos e Transporte

$17^{\circ}$ USIHC - Congresso Internacional de Ergonomia e Usabilidade de Interfaces Humano Computador

\section{OBJETIVOS}

\subsection{Geral}

Desenvolver estudos ergonômicos e antropométricos para a criação de uma tabela de medidas, seguindo os padrões de medição da ABNT (NBR 13377), que atenda as mulheres portadoras de nanismo acondroplásico, visando o bem-estar e o conforto ergonômico no uso do vestuário de acordo com as tendências da moda. Seguir as análises da anatomia das diferenças existentes em cada parte do corpo das pessoas com nanismo, com base no estudo ergonômico do biotipo dessas mulheres, para o desenvolvimento da modelagem. Investigar as dimensões corporais, para a criação de itens do vestuário, especificamente para o publico com características acondroplásicas e facilitar a construção da forma em relação a fatores estéticos, funcionais e ergonômicos.

\subsection{Específicos}

Objetivar o mapeamento do corpo em pontos específicos de mulheres adultas com nanismo do tipo acondroplásico.

Inicialmente, identificar as principais dificuldades relacionadas ao consumo do vestuário, de mulheres com nanismo, observando as características do corpo.

Desenvolver uma tabela de medidas padrão que consiga atender as necessidades básicas de conforto e bem-estar na usabilidade das peças produzidas para corpos com acondroplasia, bem como, produzir bases com estudos ergonômicos da forma.

Comprovar a importância da utilização da ergonomia e da antropometria no design da modelagem do vestuário para mulheres com corpos diferentes.

Apresentar uma tabela de medidas para modelagem ergonômica às empresas de confecção do vestuário e profissionais da moda, interessados em produzir roupas adequadas para pessoas com perfis diferentes.

Desenvolver manequins com a conformação de um corpo com características estudadas para o nanismo acondroplásico, para a utilização das técnicas de modelagem plana e tridimensional com tamanhos referenciais.

Possibilitar que a venda virtual, de roupas para o público com nanismo, tenha referências técnicas informativas para que o usuário identifique seu numero padrão de referência no ato da compra em uma plataforma.

\section{METODOLOGIA E TÉCNICAS}

Para desenvolver deste trabalho e conhecer melhor o público em questão, foi necessário realizar uma pesquisa bibliográfica a fim de identificar os conceitos e princípios do nanismo, compreender de forma correta suas principais dificuldades sociais, sua vida diária, a função do vestuário, além dos conceitos da ergonomia e a importância desta, na roupa das pessoas com nanismo. 


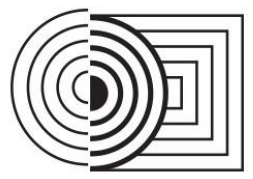

\section{$17^{\circ}$ ERGODESIGN \& USIHC 2019 \\ PUC-Rio, 11 a 13 de dezembro \\ Rio de Janeiro, RJ, Brasil}

$17^{\circ}$ Ergodesign - Congresso Internacional de Ergonomia e Usabilidade

de Interfaces Humano Tecnológica: Produto, Informações Ambientes

Construídos e Transporte

$17^{\circ}$ USIHC - Congresso Internacional de Ergonomia e Usabilidade

de Interfaces Humano Computador

A importância da ergonomia e antropometria para o vestuário, segundo IIDA (2005), os ergonomistas são as pessoas que realizam o planejamento, projeto e avaliação da tarefa, postos de trabalho, produto, ambiente e sistemas, tornando-os compatíveis com as necessidades, habitualidades e limitações dos seres humanos. Desta forma, devem analisar o trabalho de forma global, incluindo os aspectos físicos, cognitivos, sociais, organizacionais, ambiente e outros.

O trabalho dos ergonomistas deve, então, abordar características específicas do sistema. GRAVE (2010) completa o pensamento quando diz que a ergonomia considera as características físicas, fisiológicas, psicológicas e sociais, levando em consideração o sexo e a idade do indivíduo, melhorando o desempenho em suas atividades.

Os autores mencionam que a ergonomia baseada no biotipo do indivíduo, é física e estuda as características antropométricas relacionadas às atividades biomecânicas dos movimentos como andar, sentar, deitar, levantar, abraçar, pegar objetos em lugares altos, entre outros.

Toda a análise e estudo nesta área, aplicada na ergonomia do vestuário, beneficia o conforto e segurança aos usuários portadores de nanismo acondroplásico, permitindo a liberdade dos movimentos e cognitivamente a sua autoestima.

Para a pesquisa bibliográfica foi fundamental a seleção de livros, artigos, dissertações, teses e vídeos publicados na internet para levantar dados sobre o assunto, entender melhor os problemas e necessidades deste público. Foram também entrevistados médicos endocrinologistas e ortopedistas, para maiores esclarecimentos a respeito dos portadores de acondroplasia.

No que se refere ao conforto e usabilidade das roupas, para atender as necessidades de seres humanos com suas diferenças físicas e cognitivas, participaram também, pesquisadores e estudiosos sobre o assunto, mulheres com nanismo do tipo acondroplásico, designers de moda e empresários da área da indústria do vestuário, além de pessoas envolvidas em diferentes postos de um processo produtivo da moda na confecção de uma roupa.

A aplicabilidade de uma pesquisa qualitativa, sob a forma de questionário virtual para recolher dados sobre as dificuldades encontradas por mulheres portadoras de nanismo acondroplásico, com idade entre 18 a 40 anos, com relação as roupas usadas em seu dia a dia, fundamentou a necessidade da elaboração deste estudo com o foco na ergonomia do vestuário.

Os resultados das entrevistas e dos questionários serviram para orientar a segunda fase da pesquisa que tinha como objetivo desenvolver uma tabela de medidas e projetar roupas ergonomicamente corretas para atender mulheres com nanismo.

Para a construção de uma tabela de medidas, existe o método de medição através de um body scanner ou scanner de mão, com imagem tridimensional do biotipo e suas referências métricas. Porém, a tomada das medidas das mulheres com nanismo envolvidas nesta pesquisa, para este estudo, foi obtida manualmente com a utilização da fita métrica.

Dentro do universo das participantes do levantamento antropométrico, para o estudo da modelagem com análise ergonômica do corpo e de seus movimentos, foi escolhida apenas uma voluntária para que o estudo da modelagem fosse avaliado através de provas de roupas, com foco nos pontos mais críticos e para que fossem avaliados ergonomicamente os movimentos do corpo ao vestir a roupa. As medidas do corpo em estudo possibilitaram a construção de um corpo técnico sob a forma de um manequim com as características do biotipo do nanismo 
acondroplásico, utilizado para o trabalho da modelagem tridimensional, técnica que trabalha o tecido sobre o corpo, para que o cálculo dos recortes, pences e formas, sejam cognitivamente a combinação desses diversos elementos.

A elaboração da tabela abaixo demonstra uma breve análise das medidas do corpo, comparando as medições de tamanhos de corpos padrões com as do corpo acondroplásico de pesquisas publicadas, bem como, medidas tiradas de voluntárias e da modelo de prova do estudo em questão. A análise foi feita antes da elaboração dos moldes apresentados, onde, observamos que as diferenças maiores são nos membros superiores e inferiores, sendo especificamente na parte inferior, o quadril com circunferência ampla e altura do entrepernas curta. Na parte superior, o comprimento dos braços é curto e a circunferência dos bíceps é ampla. O Comprimento do tronco é bem próximo à medida do tamanho padrão considerado normal, sendo que o destaque está na altura do centro do busto, que medindo do ponto de encontro do ombro com a linha do decote, na direção do lóbulo da orelha, até o centro do busto, onde foi observada uma diferença de $3 \mathrm{~cm}$ aproximadamente para menos, se comparado com o tamanho padrão, tendo como influencia o busto pequeno comparado co o volume das costas. Outra observação foi referente à inclinação do ombro, em comparação ao padrão existente em fontes estudadas, percebendo uma diferença de aproximadamente $3 \mathrm{~cm}$, o que significa o dobro da medida de inclinação de um corpo de média padrão.

Figura 1 - Inclinação acentuada do ombro.

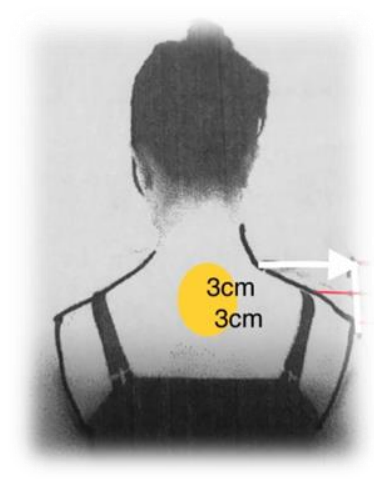

Tais medidas são fundamentais para o desenho da modelagem, porém, não foram suficientes para fazer uma adaptação às técnicas de modelagem existentes. Para um maior conforto dos usuários portadores de nanismo acondoplásico, aplicou-se o estudo da ergonomia do corpo em análise, para que a roupa exercesse a sua função. Sendo o foco da pesquisa, garantir o conforto e segurança deste usuário, permitindo que seus movimentos estejam livres de restrições, utilizando as medições ideais para a confecção de roupas ergonomicamente projetadas para este público. A tabela apresentada inicia um estudo para que seja complementado com os demais tamanhos referenciais testados através de moldes e em prova de roupas em que a modelo faça o teste de usabilidade e avalie a sua eficácia quanto ao conforto referente à ergonomia. 


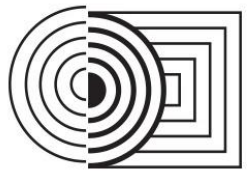

$17^{\circ}$ ERGODESIGN \& USIHC 2019

PUC-Rio, 11 a 13 de dezembro

Rio de Janeiro, RJ, Brasil

$17^{\circ}$ Ergodesign - Congresso Internacional de Ergonomia e Usabilidade de Interfaces Humano Tecnológica: Produto, Informações Ambientes Construídos e Transporte

$17^{\circ}$ USIHC - Congresso Internacional de Ergonomia e Usabilidade de Interfaces Humano Computador

\begin{tabular}{|c|c|c|c|c|c|c|c|}
\hline & SEGMENTO FEMININO & \multicolumn{4}{|c|}{ PADRÃO } & \multicolumn{2}{|c|}{ PADRÃO ACONDROPLASICO } \\
\hline & TAMANHOS & $\begin{array}{c}P \\
40\end{array}$ & $\begin{array}{l}M \\
42\end{array}$ & $\begin{array}{c}G \\
44\end{array}$ & $\begin{array}{c}\text { GG } \\
46\end{array}$ & M & MODELO DE PROVA \\
\hline 1 & ALTURA APROX. & \multicolumn{4}{|c|}{168 a 170} & 1.22 a 124 & 126 \\
\hline 2 & TÓRAX/BUSTO & 88 & 92 & 96 & 100 & 86 & 93 \\
\hline 3 & CINTURA & 68 & 72 & 76 & 80 & 74.5 & 82 \\
\hline 4 & QUADRIL & 98 & 102 & 106 & 110 & 105 & 110 \\
\hline 5 & OMBRO & 12 & 12.5 & 13 & 13.5 & 12 & 13 \\
\hline 6 & CIRC. BÍCEPS & 28 & 30 & 32 & 34 & 31 & 32 \\
\hline 7 & $\begin{array}{c}\text { ALT. BLUSA (CENTRO } \\
\text { FRENTE) }\end{array}$ & 36 & 36 & 36 & 36 & 34.5 & 34 \\
\hline 8 & ALT. CINTURA AO JOELHO & 60 & 60 & 60 & 60 & 42.5 & 45 \\
\hline 9 & $\begin{array}{l}\text { ENTREPERNAS (PARTE } \\
\text { INTERNA DA PERNA) }\end{array}$ & 77 & 77 & 77 & 77 & 37 & 41,5 \\
\hline 10 & COMPRIMENTO DE MANGA & 60 & 60 & 60 & 60 & 38 & 41 \\
\hline
\end{tabular}

FONTE: RADICETTI,E. COPPE/UFRJ (1999) Atualização: 2019. As medidas estão em centímetros.

Além da análise da tabela comparativa de medidas corpo e o estudo de observação da conformação do biotipo das mulheres portadoras de nanismo acondroplásico, foi fundamental a construção de um corpo técnico com as medidas da modelo de prova, configurado como manequim para desenvolver o desenho da modelagem tridimensional. Sobre esta base, aplicou-se o estudo da ergonomia do corpo, para que a roupa exercesse a sua função de garantir o conforto e segurança, permitindo que seus movimentos estivessem livres de restrições. Sendo este o foco da pesquisa, cada parte do corpo foi analisada e construída sob a forma de manequim, para que a roupa obtivesse o caimento tanto desejado por este publico, e o que mais se destacou foram as medidas de altura das partes do corpo que em proporções referencialmente definidas, se encaixassem ao padrão desejado. Após a elaboração da modelagem sobre o corpo técnico, foram desenvolvidas peças de roupas em sarja crua, para que os primeiros testes de caimento do molde fossem aprovados e possíveis ajustes feitos de acordo com o estilo e desejo da modelo de prova quanto a comprimento, volume, decote e recortes. Nesta fase do estudo, entre a medição do corpo, construção do manequim e confecção das roupas, observou-se uma variação da massa corporal da modelo. Em algumas publicações é considerada uma característica do nanismo. 
Figura 3- Corpo técnico feminino acondroplásico da modelo de prova.

Através da observação participativa, questionários e entrevistas semiestruturadas, foi possível elaborar a construção de moldes e as provas de roupas na modelo portadora de nanismo acondroplásico.

Para o corpo em estudo, foram desenvolvidas modelagens de bases de roupas, sendo um vestido recorte princesa por melhor acomodação das curvas do corpo com acondroplasia, uma saia justa, uma blusa com mangas compridas com recorte duplo, com uma folha superior e a outra inferior do braço, uma calça comprida e uma bermuda, formando um total de cinco peças de roupas para o armário cápsula, projetado para este estudo.

O vestido recorte princesa foi confeccionado em sarja crua com recortes e ajustes nos na curva situada na base da coluna, conformando a lordose e a acomodação do volume acentuado dos glúteos. Nesta primeira prova, foi dimensionada a medida de cava justa e caimento da linha do ombro, bem como a altura do centro do busto. O comprimento do vestido foi definido pela modelo de prova que justificou ser importante alinhar com a altura do joelho para que não influencie em sua altura, esteticamente. Uma segunda peça do vestido foi montada em tecido shangtung para a verificação e comparativo quanto ao caimento e ajustes do molde ao corpo.

Figura 4 - Vestido recorte princesa em sarja crua 


\section{$17^{\circ}$ ERGODESIGN \& USIHC 2019}

PUC-Rio, 11 a 13 de dezembro

Rio de Janeiro, RJ, Brasil $17^{\circ}$ Ergodesign - Congresso Internacional de Ergonomia e Usabilidade de Interfaces Humano Tecnológica: Produto, Informações Ambientes Construídos e Transporte

$17^{\circ}$ USIHC - Congresso Internacional de Ergonomia e Usabilidade

de Interfaces Humano Computador

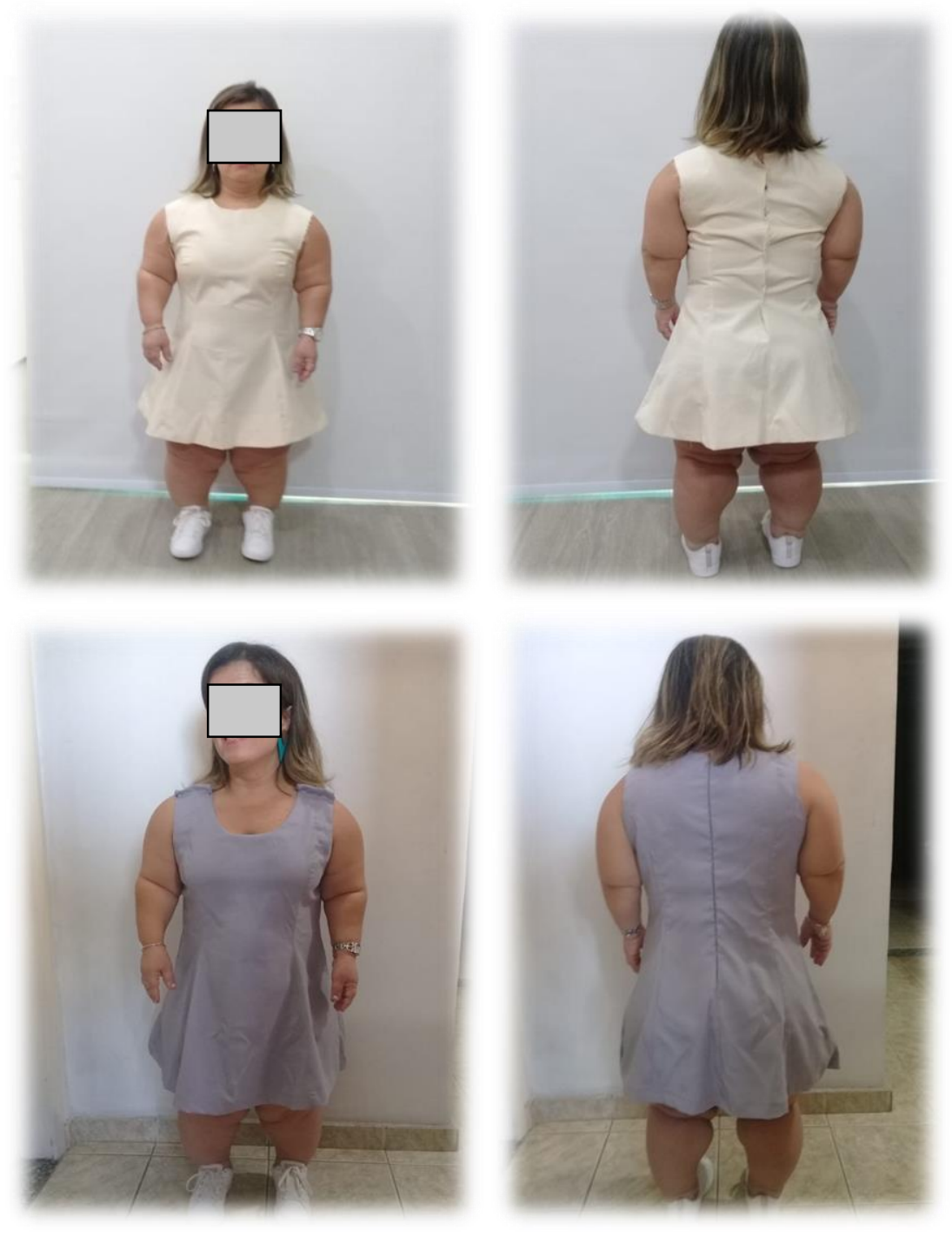

As bases de blusa e saia justas foram feitas com ajustes de alturas da cintura, curva de quadril e curva da cintura costas com a profundidade de pence estudada para o encaixe das formas mais acentuadas do corpo. A base de saia foi testada sobre o corpo da modelo, para a avaliação da modelagem, esta primeira, foi composta de duas folhas, frente e costas e com quatro pences, duas dianteiras e duas traseiras, porém, o caimento não chegou ao desejado. A segunda prova da base de saia, com as modificações feitas através de análise ergonômica para a conformação do copo acondroplásico, foi modelada sem as duas pences da frente e no centro das costas, foi feito um recorte, contemplando a curva bem acentuada da base da coluna com o volume dos glúteos, além de manter as duas pences, o que atendeu ao padrão de conforto e estética desejados. Na base de blusa, o foco foi na manga, onde o comprimento, bem como 0 diâmetro do bíceps, atende aos limites de conformação do braço que, para um conforto maior, o molde foi dividido em duas lâminas para acomodar a circunferência do bíceps ao estreitamento da cava e ao do punho, permitindo assim, que os movimentos dos braços sejam elaborados com conforto. As proporções de largura de ombro foram ajustadas a largura do costado com o foco para o ponto de tensionamento do tecido durante o movimento de cruzar os braços para 
frente, onde a folga de vestibilidade aplicada foi maior que a convencional utilizada. $A$ análise da extensão do costado em movimento para o dianteiro verificando o ponto de maior estressamento do tecido, com o foco na cava da manga, se deu através de ajustes do molde para este caso específico, portanto, a modificação elaborada melhorou a ergonomia do vestuário contemplando os movimentos do corpo.

Figura 5 - Base de blusa, manga e base de saia justa
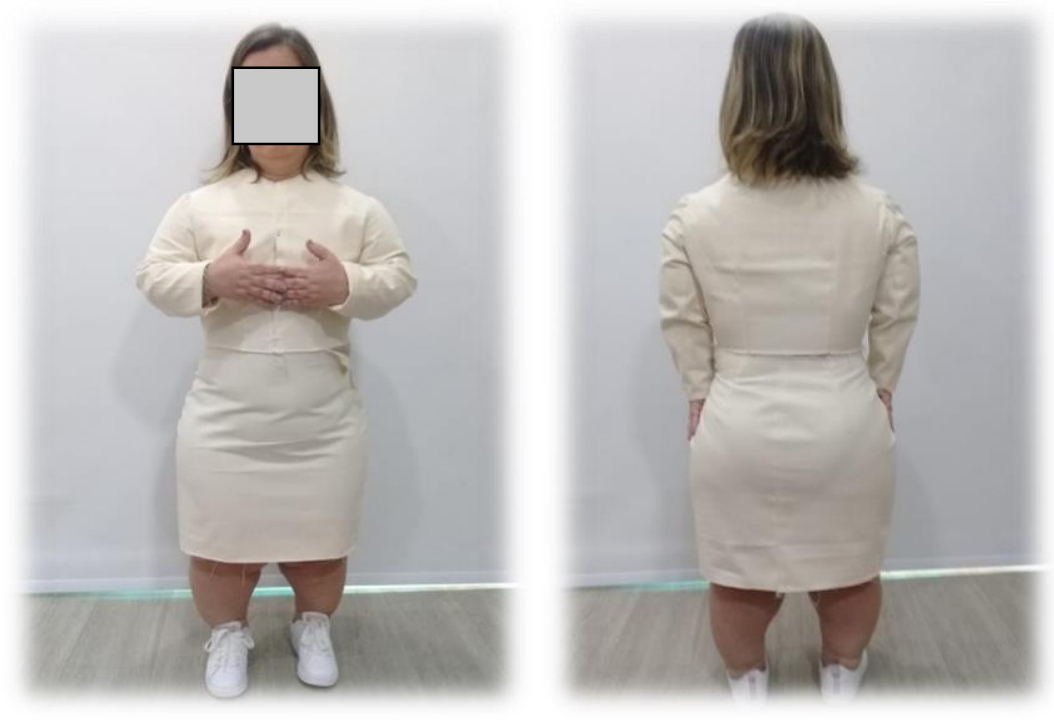

Após a prova de roupas, foi feita a modificação da medida da folga de vestibilidade no ponto que é o foco da análise do costado, no ponto e na altura de expansão das costas, marcada pelo movimento com os braços para o dianteiro, outro foco foi a cava da manga que também sofreu estressamento e precisou de ajustes com acréscimo de folga de vestibilidade.

Figura 6 - Análise da extensão do costado
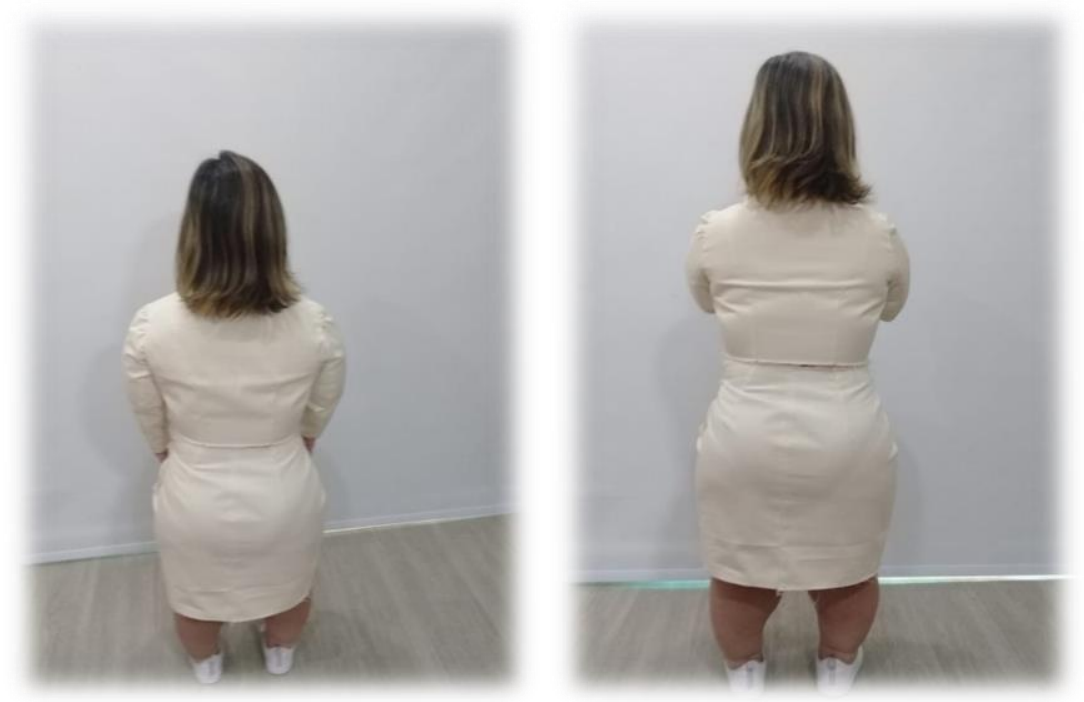
Outro ponto em análise foi a curva da cava onde também, ocorre o estresse no tecido da blusa de acordo com os movimentos, que ao levantar o braço, o tecido prende na parte do bíceps, trazendo o desconforto ao usuário.

Figura 7 - Vista em proximidade do tensionamento do ponto da cava

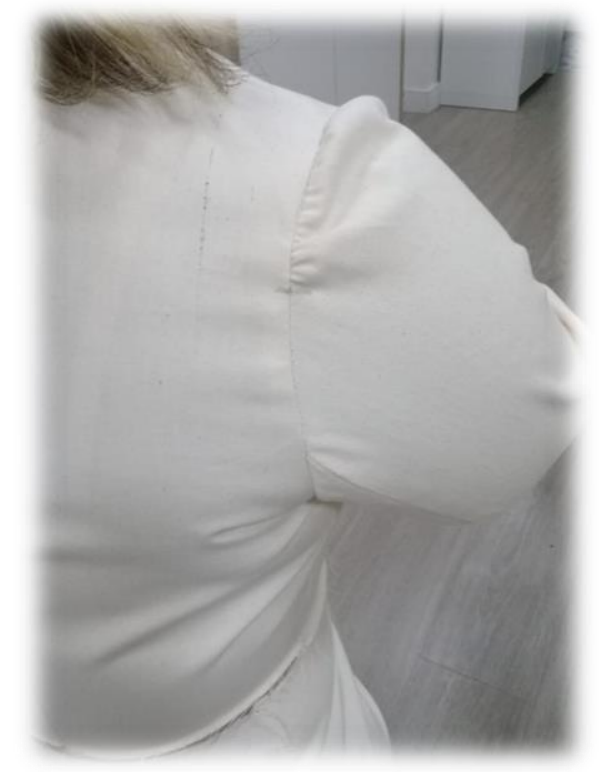

Na modelagem da calça comprida, na parte das costas, foi feita a análise da curva do gancho para a acomodação do volume glúteo. O molde foi desenhado com a curva acentuada na costura central da costas, com duas pences, tendo como opção de transformar a parte superior do traseiro da calça, em uma pala anatômica para melhor acomodar a inversão de curvas do glúteo com a lordose próxima à linha da cintura, eliminando assim, as pences. $O$ deslocamento da costura da lateral da base de calça comprida, dentro do padão normal, sofre um deslocamento de 2 a $3 \mathrm{~cm}$ para frente, porém, para o corpo de uma pessoa portadora de nanismo acondroplasico, esse deslocamento deve ser maior, partindo da linha do joelho até a linha da cintura que chega além do deslocamento padrão mais $4 \mathrm{~cm}$, somando um total de $7 \mathrm{~cm}$, para o deslocamento da linha da lateral. Observou-se que, da linha do joelho para baixo há uma curvatura para a externa das pernas, chamada varo, que deve ser contemplada no desenho do molde, para que possa além de remover o excesso de tecido acumulado próximo à barra da calça, disfarsar a curva em proporção ao alinhamento da perna, destacando neste ponto, o ajuste estético. Com base nas modificações na base de calça comprida, foi confeccionada uma bermuda que teve como resultado um bom caimento da peça sobre o corpo, assim como o conforto desejado ao caminhar e sentar.

Figura 8 - Traseiro da calça comprida com analise das curvas do gancho 
$17^{\circ}$ ERGODESIGN \& USIHC 2019

PUC-Rio, 11 a 13 de dezembro

Rio de Janeiro, RJ, Brasil $17^{\circ}$ Ergodesign - Congresso Internacional de Ergonomia e Usabilidade de Interfaces Humano Tecnológica: Produto, Informações Ambientes Construídos e Transporte

$17^{\circ}$ USIHC - Congresso Internacional de Ergonomia e Usabilidade de Interfaces Humano Computador

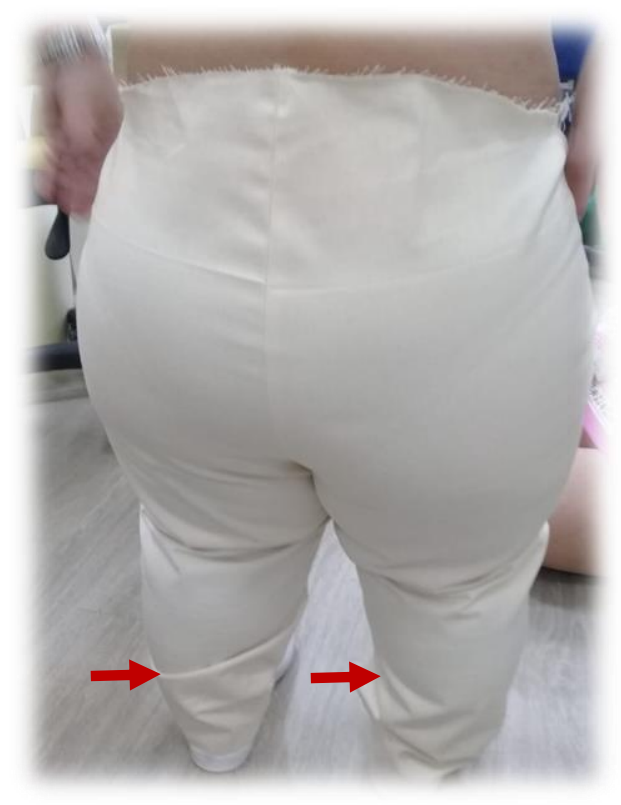

Figura 9- Análise do deslocamento da linha da lateral da calça comprida

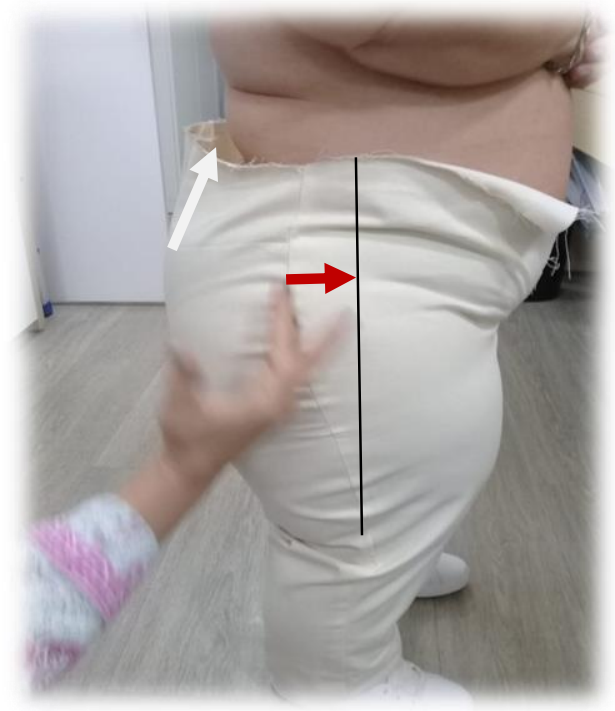

Figura 10 - Bermuda confeccionada com as mudanças analisadas na base de calça comprida. 
$17^{\circ}$ ERGODESIGN

\section{\& USIHC 2019}

PUC-Rio, 11 a 13 de dezembro

Rio de Janeiro, RJ, Brasil $17^{\circ}$ Ergodesign - Congresso Internacional de Ergonomia e Usabilidade de Interfaces Humano Tecnológica: Produto, Informações Ambientes Construídos e Transporte

$17^{\circ}$ USIHC - Congresso Internacional de Ergonomia e Usabilidade de Interfaces Humano Computador

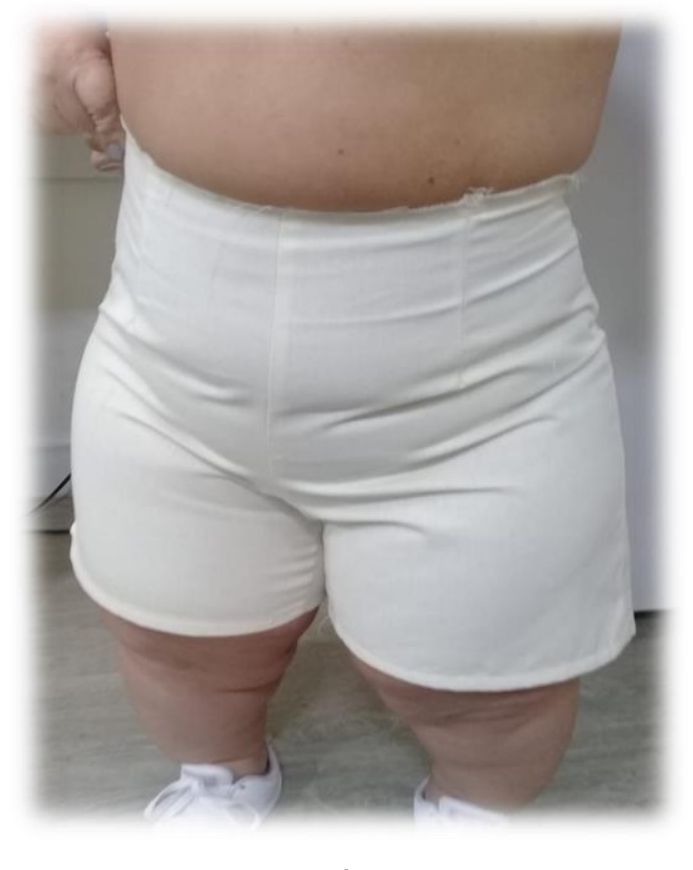

\title{
4. CONSIDERAÇÔES FINAIS
}

As modelagens foram concluídas e adequada para a conformação das curvas do corpo das mulheres portadora de nanismo acondroplásico com o foco na ergonomia do vestuário. Considerando o futuro da indústria da moda para a compra através de lojas virtuais em que o cliente escolhe a roupa da coleção, a cor e os detalhes, e a cabine de prova passa a ser um 3D body scaner , que envia as informações de medição do corpo para que as roupas sejam ajustadas de acordo com o biotipo do cliente, adequando a modelagem às suas medidas, a possibilidade existe e testes são elaborados pela $\mathrm{TC}^{2}$, centro de tecnologia da Carolina do Norte, que a cada dia avança em suas pesquisas para que essa modalidade seja portada em um mobile 3D body scaner, que atenderá em larga escala as necessidades de um novo tipo de consumo para o mercado da moda. As pesquisas avançam e com este estudo, haverá a contribuição para que maiores informações sejam inseridas a fim de tornar possível a inclusão dos portadores de acondroplasia, para o consumo no mesmo mercado de roupas desenvolvidas para biotipos considerados padrão, onde as empresas que produzem a roupa para a marca irão receber informações das características dos clientes e terão em seus sistemas ou arquivos de modelagem, as bases dos moldes para portadores de nanismo acondroplásico, com as informações dos pontos críticos encontrados nesta pesquisa.

\section{REFERÊNCIAS BIBLIOGRÁFICAS}

\author{
CAPELASSI. Carla Hidalao. Metodoloaia proiectual para produtos de moda \\ e a sua interface com as tabelas de medidas do vestuário. Dissertação \\ (Mestrado) - Universidade Estadual Paulista. Faculdade de Arquitetura, Artes e
}


Comunicação, Bauru, 2010

CERVAN, Mariana Pereira; SILVA, Márcia Cristina Pires da; LIMA, Rodrigo Lopes de Oliveira; COSTA, Roberto Fernandes da. Estudo Comparativo do nível de qualidade de vida entre sujeitos acondroplásicos e não acondroplásicos. Jornal brasileiro de Psiquiatria [online]. 2008, vol.57.

CASUSCELLI, Carina. A moda está em baixa. São Paulo, 2011.

GRAVE, Maria de Fátima. A modelagem sob a ótica da ergonomia. São Paulo: Zennex, 2004.

FURTADO, MOREIRA LOUISIE. Desenvolvimento de vestuário ergonômico para mulheres portadoras de nanismo. SEPesq, Porto Alegre, Rio Grande do Sul, 2015.

GONZALEZ, C.H.; MARCONDES, E. Caso em foco: acondroplasia. Pediat. São Paulo 4:62-66 1982.

IIDA, Itiro. Ergonomia: Projeto e produção. São Paulo. Blücher, 2005.

KÖRBES, Rafael; LASCHUK, Tatiana; COSTA, Thays Neves. Estudo de Modelagem Plana para pessoas com nanismo. In: 10ํㅡㅁóquio de Moda, 2014, Caxias do Sul. 10 Colóquio de Moda, 2014 - 7aㅡ Edição Internacional. 1ํㅡ Congresso Brasileiro de Iniciação Científica em Design e Moda, 2014.

LIGER, Ilce. Moda em 360 Design, Matéria Prima e Produção para o Mercado

Global. São Paulo: Editora Senac São Paulo, 2012.

MELO, A.M.; BARANAUSKAS, M.C.C. (2006). Design para a Inclusão: desafios e proposta. In: Simpósio sobre Fatores Humanos em Sistema Computacionais, Natal, RN, pp. 11 - 20.

PIRES, Dorotéia Baduy (Org.). Design de moda: olhares diversos. Barueri: Estação das Letras e Cores, 2008. $423 p$

RADICETTI, Elaine. Padronização do biotipo do brasileiro para a indústria do vestuário. COPPE-UFRJ, 1999.

SABRÁ, Flávio. Modelagem: Tecnologia em produção de vestuário. São Paulo: Estação das letras e cores, 2009.

SOUZA, Sergio de, Tipos de Nanismo. Hype Science [online], 2012.

\section{AGRADECIMENTO}

Pontifícia Universidade Católica Rio, Senai Cetiqt, Universidade CEUMA - MA, Draft Manequins Industriais, Fabrícia Silva de Carvalho (modelo). 